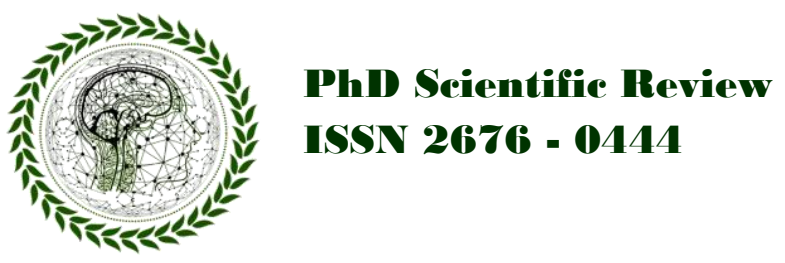

Artigo submetido em: 11/06/2021

Artigo aceito em: 14/06/2021

Artigo publicado em: 24/06/2021

\title{
Implicações da boa convivência e afetividade no processo de ensino-aprendizagem: Relação Professor-Aluno
}

\section{RESUMO}

\author{
Marcus Antônio Santiago ${ }^{1}$
}

O presente tema estudado justifica-se pela necessidade de identificar e mostrar como acontece a relação entre professor e aluno. Buscando entender a importância dessa relação no processo de ensino - aprendizagem. Para isso é importante identificar os pontos relevantes, que possam estimular o professor e aluno para que haja uma boa convivência e afetividade no processo educativo, levando a uma educação de qualidade. Para embasar todo estudo, foi utilizado no processo metodológico uma pesquisa bibliográfica com autores conceituados, que possuem ligação com o tema. Assim, para uma melhor compreensão da relação professor/aluno atentou-se um buscar subsídios que poderão responder algumas dúvidas. Diante disso no percurso deste trabalho será relatado quanto a interação entre educador e educando é importante para o processo, de ensino/ aprendizagem.

Palavras-chave: Aprendizagem. Afetividade. Relação Aluno-Professor.

\begin{abstract}
The present theme studied is justified by the need to identify and show how the relationship between teacher and student happens. Seeking to understand the importance of this relationship in the teaching - learning process. For this, it is important to identify the relevant points that can stimulate the teacher and student so that there is a good coexistence and affection in the educational process, leading to quality education. To support the whole study, a bibliographic search with renowned authors, who have a connection with the theme, was used in the methodological process. Thus, for a better understanding of the teacher / student relationship, an attempt was made to seek subsidies that may answer some questions. Therefore, in the course of this work, it will be reported how much the interaction between educator and student is important for the teaching / learning process.
\end{abstract}

Keywords: Learning. Affectivity. Student-Teacher Relationship.

${ }^{1}$ Professor na rede pública estadual de ensino. Graduado em Filosofia, Pedagogia, Teologia, Educação Física. Pósgraduado em Gestão Escolar, Ciências da Religião, Educação Empreendedora. Especialista em educação básica/supervisor pedagógico.msantibaniz@gmail.com 


\section{INTRODUÇÃO}

Vivemos a era da globalização, da liberdade, onde a tecnologia está cada vez mais inserida na vida das pessoas, a comunicação atinge as massas das mais diversas formas através dos meios de comunicação que chega, em muitos casos, em tempo real. Novas formas de comunicação e novas maneiras de se comunicar surgem com uma grande velocidade. São esses meios, também, formadores de opinião que muitas vezes determinam quais padrões e estilos devem ser seguidos. No entanto, não devemos esquecer que a educação é a grande responsável em ajudar na formação do indivíduo, capaz de analisar, criticar e definir suas próprias escolhas.

A Educação é a base para ajudar a melhorar o país em que vivemos, pois ela é capaz de criar e difundir a justiça social, para eliminar os problemas sociais que enfrentamos hoje em dia. Mas é só será possível haver uma educação de qualidade se o transferidor do conhecimento estiver comprometido com a sala de aula. O professor deve ser de criar com um aluno uma relação de cumplicidade onde este se sinta seguro a aprender, e aquele a ensinar. $\mathrm{O}$ ambiente escolar deve ser um espaço aberto à reflexão, a crítica, a curiosidade, ao questionamento, a descoberta de novos saberes, enfim, onde haja uma troca de saberes.

O professor deve reconhecer e respeitar o desenvolvimento de cada aluno, pois cada ser possui suas próprias experiências, conhecimentos e características únicas que formam um modo ser peculiar, sendo que cada indivíduo tem sua "bagagem", interpretando e vendo as coisas de maneira diferente dos outros. A relação professor/ aluno deve ser de respeito mútuo, construída na base da confiança e da amizade. O professor deve fornecer ao aluno alicerces sólidos para que seja possível a aprendizagem, levando em conta que cada aluno possui um ritmo, e o professor como bom observador, deverá perceber e definir a melhor estratégia para lidar com essas diferenças.

O contato criado entre professores e alunos é o ponto alto do processo pedagógico. Sendo impossível desagrupar a realidade escolar da realidade "de mundo". Deve se criar um espaço onde professor e aluno aprendam, e possam trocar experiências de vida e conhecimento, um espaço no qual a criança sinta liberdade em se expressar, ciente que ali não existem preconceitos ou críticas ao seu modo de ser e pensar, mas sim de apoio e ensinamento que visem seu crescimento pessoal. 
Os professores devem ser transformadores e buscarem oportunidades para que os alunos cresçam e se desenvolvam em todos os sentidos, sempre procurando novos métodos. É preciso despertar no aluno essa vontade de buscar o novo o desconhecido, o professor deve despertar o desejo de aprender, de conhecer a infinidade de saberes e prazeres que isto pode proporcionar.

A pesquisa foca principalmente na relação professor/ aluno e nos benefícios que esse tipo de ligação resulta, mostrando que essa relação é a base para que o aluno aprenda de forma correta, e utilize de seu potencial para se tornar uma pessoa crítica e interligada com o mundo e suas relações.

O referido trabalho parte da referência bibliográfica dos pensadores: Vygotsky, Freire, Libâneo entre outros a fim de fundamentar o tema da pesquisa.

\section{DESENVOLVIMENTO}

A relação que nossos pais tiveram com seus professores, foi diferente da qual nós tivemos e também é diferente das quais os alunos tem hoje. Essa relação de antigamente é vista como um padrão onde o professor falava e o aluno ouvia, era exigido silêncio sendo inconcebível haver diálogo entre mestre e aluno. Essa relação acontecia de forma autoritária, a figura do professor representava a autoridade e a obtenção do conteúdo acontecia através da memorização. O ensino era visto como algo que exigia disciplina, onde se devia assimilar e reproduzir os conhecimentos transmitidos pelo educador. Grandes pensadores ilustram isso, como por exemplo, Einstein, Castro Alves, Carlos Drummond de Andrade e Frei Beto, que durante o período escolar, questionaram e foram reprimidos. Isso mostra a necessidade de ruptura desses velhos padrões, e a criação de um espaco aberto ao diálogo. Sobre esse assunto Rego (2001, p. 46) mostra que:

\footnotetext{
"Os postulados de Vygotsky parecem apontar para a necessidade de criação de uma escola bem diferente da que conhecemos. Uma escola em que as pessoas possam dialogar duvidar, discutir, questionar e compartilhar saberes. Onde há espaço para transformações, para as diferenças, para o erro, para as contradições, para a colaboração mútua e para a criatividade. Uma escola em que os professores e alunos tenham autonomia, possam pensar, refletir sobre o seu próprio processo de construção de conhecimentos e ter acesso a novas informações. Uma escola em que o conhecimento já sistematizado não é tratado de forma dogmática e esvaziado de significado."
} 
Felizmente esse modelo ficou ultrapassado, sendo permitido ao aluno a oportunidade de se comunicar, questionar e estreitar a relação com seus professores. Essas experiências vivenciadas na escola e por meio dela, tem um importante significado para o desenvolvimento social e afetivo. Quando o aluno recebe por parte do professor, um espaço para se comunicar expondo suas hipóteses e construções, nasce ai um relacionamento produtivo entre ambos. Esse ambiente também permite ao aluno desenvolver idéias criativas e relevantes. Libâneo (1994, p.250) acredita que:

\footnotetext{
“O professor não apenas transmite uma informação ou faz perguntas, mas também ouve os alunos. Deve dar-lhes atenção e cuidar para que aprendam a expressar-se, a expor opiniões e dar respostas. O trabalho docente nunca é unidirecional. As respostas e as opiniões dos alunos mostram como eles estão reagindo à atuação do professor, às dificuldades que encontram na assimilação dos conhecimentos. Servem também para diagnosticar as causas que dão origem a essas dificuldades."
}

Quando o aluno capta o conhecimento passado pelo professor, não significa que ele será um mero repetidor desse conhecimento. Se existir uma relação de confiança aluno/professor essas informações terão espaço para discussão, aprofundamento e análise sobre as perspectivas de ambos. Essa interação é um aspecto importante para desenvolver a aprendizagem, pois ela abre portas de acesso ao interesse do aluno, facilitando a exposição do conteúdo. Essa afinidade aluno/professor ganha espaço para se construir uma relação que sai do âmbito escolar, indo além do aspecto pedagógico. Cria-se uma ligação de admiração mútua que acontece por sermos seres humanos que necessitam de estabelecer vínculos afetivos com quem nos cerca.

Este intercâmbio (aluno/professor) veio suprir a concepção bancária da educação, que é o ato de "depositar", onde o professor detentor de todo conhecimento deposita nos alunos suas informações. Estes por sua vez cabem apenas arquivar o que ouviram ou copiaram. È a concepção "acumulativa” da educação (concepção bancária). Há professores que utilizam esse método bancário seja de forma consciente ou inconsciente, isso impede uma consciência crítica por parte dos alunos. Criam-se indivíduos com dificuldade para questionar e sem curiosidade, incapaz de pensar e agir por conta própria.

Quando o professor se preocupa apenas em ensinar, ele não tem paciência necessária para esperar que a criança aprenda, contextualize as informações recebidas e dê sua resposta, o 
professor de imediato da a resposta correta. Isso faz com que a criança perca a oportunidade de acompanhar o raciocínio, tendo suas atividades dirigidas e canalizadas, caindo no método do ensino tradicional, frustrando-a, já que ela se sente incapaz. O professor deve enxergar no erro do aluno um processo de aprendizagem, quando o educando erra, o professor pode identificar o que ele sabe e o que ainda deve ser ensinado. Por isso deve observar e buscar compreender as experiências que o aluno já possui e está transmitindo, Vigotski (2003, p.77):

\begin{abstract}
“Educação é realizada através da própria experiência do aluno, que é totalmente determinada pelo ambiente; a função do professor se reduz à organização e à regulação de tal ambiente. O que indica que o professor deve buscar o fazer pensar e propiciar a reflexão crítica e coletiva em sala de aula, ou seja, uma verdadeira atividade interativa que possibilite processos mentais superiores. No pensamento de Vigotski torna-se essencial sabermos que a intervenção do professor não pode estar muito abaixo do desenvolvimento real do aluno, nem muito acima do potencial, o que significa em esforço para poder atingir a zona de desenvolvimento proximal de cada um presente na sala de aula."
\end{abstract}

As relações humanas são normalmente complexas, mas são peças importantes na formação comportamental e profissional de uma pessoa, são essas relações que ajudam a moldar e construir o caráter e comportamento do indivíduo, sejam elas familiares, escolares, afetivas, profissionais, etc., elas sempre interferem na maneira de ser e viver do outro. A afinidade professor/aluno possui uma interação que se caracteriza pela seleção de conteúdos e organização que facilitam o aprendizado (aluno) e exposição (professor).

O professor deve entender que formar alunos é ajudá-lo a encontrar o próprio caminho, a transformar-se, evoluir, refletir, mover-se e relacionar-se. Indo além da sala de aula, pois mais que alunos, ele ajuda a formar cidadãs. Ele deve achar assuntos que despertem o interesse do aluno, sendo um mediador, um facilitador no processo de formação, os temas devem abranger além da disciplina a ser lecionada, fatos e realidades que se encaixem no "mundo" dos alunos, de forma que eles possam contextualizar e perceber a importância do conhecimento adquirido para o dia-adia e toda a vida deles, buscando descobrir sempre coisas novas. Para João Paulo Souza Silva, no artigo Relação Professor/Aluno no processo de ensino e aprendizagem:

\footnotetext{
“O prazer pelo aprender não é uma atividade que surge espontaneamente nos alunos, pois, não é uma tarefa que cumprem com satisfação, sendo em alguns casos encarada como obrigação. Para que isto possa ser melhor cultivado, o professor deve despertar a curiosidade dos alunos, acompanhando suas ações no desenvolver das atividades." (2005, p.12)
} 
Cada professor possui uma bagagem com experiências e conhecimentos obtidos ao longo de sua vida pessoal e profissional. De modo consciente ou não, esta bagagem altera a forma de aprender, ensinar e ver o mundo. É importante ao educador não colocar-se na posição de detentor do saber, quando colocar em prática o diálogo, visto que sempre temos algo a aprender, mesmo com aqueles que julgamos menos sábios, pois o "saber" vem de várias maneiras, esta enraizado na cultura e vivência de cada ser. ABREU \& MASETTO (1990: 115), afirma que "éo modo de agir do professor em sala de aula, mais do que suas características de personalidade que colabora para uma adequada aprendizagem dos alunos; fundamenta-se numa determinada concepção do papel do professor, que por sua vez. reflete valores e padrões da sociedade".

A relação professor/ aluno depende da abertura que o professor estabelece, da capacidade de interação, de ouvir e discutir, criando um elo entre eles. Para Freire (2002) "o educador que escuta aprende a difícil lição de transformar o seu discurso, às vezes necessário, ao aluno, em uma fala com ele." O bom professor deve ser capaz de trabalhar o lado produtivo dos alunos para que sejam capazes de se tornar cidadãos atentos a suas responsabilidades sociais, pois de certa maneira a escola, depois da família é o contato social que mais interfere na formação da criança, que segundo as experiências que sofre nessa fase, vai determinar o tipo de adolescente e adulto que serão inseridos na sociedade, com obrigações e deveres. Segundo Freire (1996, p.96)

\footnotetext{
"O bom professor é o que consegue, enquanto fala, trazer o aluno até a intimidade do movimento do seu pensamento. Sua aula é assim um desafio e não uma cantiga de ninar. Seus alunos cansam, não dormem. Cansam porque acompanham as idas e vindas de seu pensamento, surpreendem suas pausas, suas dúvidas, suas incertezas."
}

Para que o processo de aprendizagem ocorra é importante que o professor tenha consciência de sua função diante do aluno. O educador deve criar uma relação de cooperação e respeito frente ao aluno. Ele deve apresentar condições favoráveis para o aluno agir, dando apoio moral, segurança e confiança. O professor e os colegas representam um grupo de mediadores da cultura que vão ajudar o educando no processo de desenvolvimento. A figura do educador tem um valor muito grande para educado, dois fatores ganham destaque para GANDOTTI (1999, p.29) que acredita que "o primeiro está relacionado à importância que o aluno atribuir à opinião que o professor tem sobre ele, quanto maior for à importancia e significativa, maior será a probabilidade de que lhe afete o segundo fator refere-se ao conceito que o aluno tem de si mesmo e de sua própria capacidade". 
As expectativas fazem parte da natureza humana, isso também acontece por parte dos alunos que esperam um comportamento padrão por parte do professor. Este também cria essa expectativa em relação ao aluno, tendo um peso maior, pois o desempenho do aluno pode estar diretamente ligado à relação à expectativa do professor quanto a ele.

Cada aluno possui um perfil e a partir disso cria sua própria expectativa e um modo de interagir com os outros e com o professor. Este pode notar isso ao observar uma apresentação ou a reação de cada aluno a um exercício. Cabe a ele também identificar e se adaptar ao estilo de aprendizado do aluno e criar uma aula mista, pois isso irá agradar a perfis diferentes, dando oportunidade a todos de interagir e acompanhar a aula, sem se sentir prejudicado ou excluído. Com o passar do tempo, os alunos irão criar uma identidade média facilitando o trabalho do professor.

Assim como existem alunos com características diferentes, o mesmo ocorre com os professores, que possuem características e comportamento próprios. A personalidade interfere na maneira de lecionar e encarar os problemas que surgem, pois, muitos professores ainda não conseguem ser neutros dentro do ambiente de trabalho e acabam passando seus medos, frustrações e descontentamento para os alunos. É preciso dosar as emoções e demonstrações do estado emocional dentro da sala de aula, pois isso interfere diretamente no modo do aluno ver seu "mestre" e no aprendizado. A paixão pela profissão e carinho do educador pelos alunos é que vai ajudar a tornar o ambiente agradável, harmônico, estimulando de maneira saudável o aprendizado. De acordo com Freire (2002, p.78) existem vários tipos de professor, e todos eles deixam sua marca, assim o autor expõe que:

"O professor autoritário, o professor licencioso, o professor competente, sério, o professor incompetente, irresponsável, o professor amoroso da vida e das gentes, o professor mal-amado, sempre com raiva do mundo e das pessoas, frio, burocrático, racionalista, nenbum deles passa pelos alunos sem deixar sua marca."

Independente do tipo de denominação que o professor receba devido a suas características, ele é uma figura fundamental e de grande importância no processo educacional. Ele deve ensinar não apenas o conteúdo, mas também ensinar ao aluno a pensar de forma correta, pois isso proporciona aos educando a visão da importância de estarmos no mundo e com o mundo. 
A função do professor está muito atrelada a função da escola, que tem sido considerada um espaço dotado da missão de formar cidadãos conscientes e agentes por meio do processo educacional, e não apenas passar conhecimento. Com base na mesma lógica, Freire (1996, p.98) afirma que: uma das tarefas da escola, como centro de produção sistemática de conhecimento, é trabalhar criticamente a inteligibilidade das coisas e dos fatos e a sua comunicabilidade. Ele revela ainda que "o educando deve assumir seu papel de sujeito da produção de sua inteligência do mundo e não apenas o de recebedor da que lhe seja transferida pelo professor." O professor deve ajudar o aluno a se ver como um ser capaz de construir seu próprio conhecimento.

O processo ensino -aprendizagem contem 4 elementos fundamentais que são: o aluno, a escola, o professor e o conteúdo. O aluno é detentor da capacidade, inteligência e velocidade para captar conhecimentos diferentes, ele vai captar em maior proporção o conteúdo que lhe for mais interessante. O professor é o transmissor do conhecimento, ele tem como função repassar esse saber. Mas deve-se levar em consideração que o educando também é um espaço de informação que possui gostos, culturas, aptidões diferentes, em determinados momentos este chega a ser uma fonte de informação para o professor.

A relação professor/ aluno também passa por conflitos, pois existem nela idéias opostas, onde cada um defende seu ponto de vista. Mas é importante nessa relação construir uma interação, onde cada um da sua contribuição, o melhor espaço isso acontecer é a sala de aula. Quando professores e alunos realizam atividades comuns, trabalham de forma mais cooperativa, resultando em trabalhos mais significativos.

Para entender como se da relação professor/aluno é preciso compreender que emoção e afetividade não são a mesma coisa. Para Wallon (1986) as emoções são sentimentos subjetivos com ligação orgânica, como choro, fome, desconforto, alegria, em geral suas alterações provocam alguma mudança muscular. Já a afetividade é mais ampla e tem ligação com os sentimentos, é de ordem psicológica. É com seu aparecimento que ocorre às transformações das emoções em sentimentos.

A aprendizagem acontece a partir das interações entre as pessoas, onde o indivíduo adquire novas formas de pensar e agir e a partir daí constrói novos conhecimentos. É importante analisar as interações que ocorrem dentro da sala de aula, pois esse intercâmbio influencia no processo de aprendizagem. 
A proximidade física entre professor e aluno contribui para transmitir segurança e tranqüilidade diante das atividades em sala. Também colabora para criar diálogos, amenizando a ansiedade e transmitindo confiança para o aluno, que com isso se torna mais encorajado para realizar as atividades. De acordo com Almeida (1999, p. 78), como não se pode separar o pedagógico do bumano, a qualidade de todo o processo de ensinar e de aprender, decorre do tipo de relações interpessoais que são mantidas em sala de aula. A Pedagogia do afeto procura aplicar uma didática em sala de aula que possa criar afetividade nas relações dos docentes e discentes, de modo a melhorar a qualidade dos relacionamentos e a produtividade em sala de aula.

A afetividade não é apenas demonstração de carinho físico ou elogios, são formas de expressão que utilizam o corpo, os olhos, a voz, o toque.

“Com o advento da função simbólica que garante formas de preservação dos objetos
ausentes, a afetividade se enriquece com novos canais de expressão. Não mais restrita à
trocas dos corpos, ela agora pode ser nutrida através de todas as possibilidades de
expressão que servem também à atividade cognitiva." (Dantas, 1993, p. 75).

Quando o professor é sereno e tranquilo o aluno capta esses sentimentos e isso ajuda a reduzir ou até mesmo acabar com sentimentos como medo, angustia e frustração por parte do aluno. Quando há compreensão por parte do professor, aceitação e valorização pelo aluno, as experiências em sala de aula ganham marcas positivas, favorecendo a autonomia dos alunos em tomar decisões. O professor tem o dever de estimular o espírito de cooperação e solidariedade, que vão resultar em um trabalho em equipe. Pois assim é possível ao aluno perceber a escola como um ambiente de aprendizagem diferente de casa. A escola exerce um papel fundamental no desenvolvimento socioafetivo da criança. Segundo Almeida (1999, p. 99):

\footnotetext{
“Como meio social, é um ambiente diferente da família, porém bastante propício ao seu desenvolvimento, pois é diversificado, rico em interações, e permite à criança estabelecer relações simétricas entre parceiros da mesma idade e assimetria entre adultos. Ao contrário da família, na qual a sua posição é fixa, na escola ela dispõe de uma maior mobilidade, sendo possível a diversidade de papéis e posições. Dessa forma, o professor e os colegas são interlocutores permanentes tanto no desenvolvimento intelectual como do caráter da criança, o que poderá ser preenchido individual e socialmente.”
}

Para que haja um ensino de qualidade é importante o entusiasmo pessoal do professor que pode transformar e doar o amor a ciência e aos alunos. Estes educadores tem como maior objetivo o ato de ensinar, contribuindo para que os alunos se sintam motivados a aprender. Que 
eles criem iniciativas e busquem novos conhecimentos que lhes tragam uma melhor visão da vida cotidiana. Segundo Rey (2001, p.96) "Um dos objetivos da educação não é simplesmente o de efetivar um saber na pessoa, mas seu desenvolvimento como sujeito capaz. de atuar no processo em que aprende e de ser parte ativa dos processos de subjetivação associados à sua vida cotidiana."

Para ajudar a melhorar a relação de aprendizagem e afetividade entre professores e alunos, Almeida (1999, p. 93) estabelece alguns princípios:

“-Estabeleça metas individuais. Isso permite que os alunos desenvolvam seu próprio critério de sucesso.

- Emoções positivas melhoram a motivação. Se você pode tornar alguma coisa engraçada ou emocionante, sua turma tende a aprender muito mais.

- Demonstre por meio de suas ações que o aprendizado pode ser agradável.

- Desperte na criança o desejo de aprender.

- Dê atenção. Mostre ao aluno que você se importa com o progresso dele. Ser indiferente a uma criança é um poderoso desmotivador.

- Negocie regras para o desenvolvimento do trabalho.

- Mostre como o conteúdo pode ser aplicado na vida real.

- Explique sempre os objetivos da atividade.

- Em vez de recriminar respostas ou atitudes erradas, reconheça o trabalho bem-feito.

- Sempre que possível ofereça opções de atividades.

- Seja flexível ao ensinar. Apresente exemplos para estimular a reflexão.”

O professor é visto como facilitador da aprendizagem, aberto às novas experiências, procura compreender, numa relação saudável, respeitando também os sentimentos e os problemas de seus alunos tentando levá-los à auto realização.

A relação entre professor e aluno deve acontecer num clima que facilite ao aluno aprender. Para facilitar o aprendizado do aluno, os professores, segundo Vygotsky, Freire, Libâneo, entre outros, devem ter suas qualidades bem desenvolvidas, sendo elas: autenticidade, apreço ao aprendiz, compreensão e principalmente amor pela profissão. 


\section{CONSIDERAÇÕES FINAIS}

As manifestações de afetividade exercem um papel fundamental no processo de desenvolvimento do aluno. A relação professor/ aluno deve acontecer baseada no respeito, na confiança e na liberdade de pensamento. Para Bossa (2000, p. 18): “(...) o sentidos das aprendizagens é único e particular na vida de cada um, e que inúmeros são os fatores afetivos emocionais que podem impedir o investimento energético necessário às aquisições escolares.”

A relação entre inteligência e afetividade, razão e emoção no desenvolvimento do aluno e no contexto da educação estão inteiramente ligadas ao desempenho escolar. É importante estar atento ao lado afetivo e o papel que este representa, dando importância também ao meio onde este acontece e as pessoas que estão envolvidas. Segundo Almeida (1999, p. 91), “[... é épreciso que o professor esteja muito atento aos movimentos das crianças, pois estes podem ser indicadores de estados emocionais que devem ser levados em conta no contexto de sala de aula."

Quando há a falta de uma educação de qualidade seja na sala de aula, na família ou na própria sociedade, os prejuízos são muitos. Quando essa ausência da educação mexe com o emocional do aluno os prejuízos são maiores, e não poderão ser corrigidos por uma ação pedagógica.

O professor deve ser visto inclusive por ele próprio como um facilitador no processo de aprendizagem. Sua relação com o aluno deve ter vínculos de afeto e cumplicidade e respeito aos outros. O educador deve propiciar ao aluno a oportunidade de mostrar, criar, questionar, mostrando o que ele sabe, e permitindo ao professor aprender com ele. Sendo possível, é importante haver uma relação que ultrapassa o nível acadêmico e permite que ocorra um olhar diferenciado em direção ao desconhecido. É necessário refletir constantemente acerca das potencialidades do discente e da relação entre a afetividade e o conhecimento.

$\mathrm{O}$ aluno, enquanto aprendiz deve estar atento às emoções envolvidas em sua aprendizagem, a fim de encontrar formas de direcioná-las a uma aprendizagem significativa. Só há relação professor-aluno se houver amizade. O aluno precisa confiar, respeitar e considerar o professor e isso só acontece quando se tornam amigos. Professor que não respeita cria um bloqueio que impossibilita a aprendizagem. Cabendo aos professores construírem com o papel de afetividade no desenvolvimento da criança, onde sejam trabalhadas as emoções de forma 
prazerosa, pois o resultado do trabalho com essas emoções pode resultar em grandes aprendizagens significativas, na escola.

\section{REFERÊNCIAS}

ABREU, Maria C. \& MASETTO, M. T. O professor universitário em aula. São Paulo: MG Editores Associados, 1990.

ALMEIDA, A. R. S., A emoção na sala de aula. Campinas, SP: Papirus, 1999.

DANTAS, H. Afetividade e a construção do sujeito na psicogenética de Wallon: teorias psicogenéticas em discussão. São Paulo: Summus Editorial Ltda, 1993.

FREIRE, Paulo. Pedagogia da autonomia: Saberes necessários à prática educativa. São Paulo: Paz e Terra, 1996.

Paulo. Pedagogia da autonomia: saberes necessários à prática educativa. $21^{a}$ Edição- São Paulo: Editora Paz e Terra, 2002.

GADOTTI, M. Convite à leitura de Paulo Freire. São Paulo: Scipione, 1999.

LIBÂNEO, José Carlos. Didática. 13 Ed. São Paulo: Cortez, 1994.

REGO, T. C. Vygotsky: Uma perspectiva histórico-cultural da educação. Petrópolis: Vozes, 2001.

REY, F.G. Comunicação e personalidade. Havana: Pueblo Educación, 1995.

SILVA, João Paulo Souza. A relação Professor/Aluno no processo de ensino e aprendizagem. Revista Espaço Acadêmico, 2005.

VIGOTSKI, L. S. Psicologia pedagógica. Porto Alegre: Artmed, 2003.

WALLON, H., Psicologia. São Paulo: Editora Ática, 1986. 